ERRATUM

Vinciane Régnier · Gisèle Danglot · Van-Cong Nguyen

Alain Bernheim

\title{
A Tsp509I variant in exon 13 of the neurofibromatosis type 1 (NF1) gene allows the identification of both alleles at the mRNA level
}

Hum Genet (1995) 96:131-132

An unfortunate error occurred in the presentation of the alternative bases in the Tsp509I polymorphism. The residues at position 2034, reported as $\mathrm{C}$ and $\mathrm{A}$, were actually $G$ and $A$. The correct version reads:
The residues found at position 2034 are $G$ (frequency: 0.71 ) and A (frequency: 0.29). Both codons (CCG and CCA) still encode proline. 